\title{
Enhancing cognitive learning in Veterinary Osteology through student participation in skeleton preparation project
}

\author{
Melaku Tefera, \\ College of Veterinary Medicine, Haramaya University. P. O. Box 144 Haramaya Campus. Ethio- \\ pia.251-0914722459, <melaku22@yahoo.com>
}

\begin{abstract}
Despite anatomy is considered the language of medicine, the 21 st century veterinary curriculum has often shown to reduce the hours dedicated towards anatomy education and new teaching methods should be introduced. This study is focused at Veterinary anatomy education. The objective was to assess the importance of student participation in skeletal preparation. The hypothesis that the students would be more interested in the discipline if the teaching methodology used is based on creative and constructivist methods. Thirteen animal skeletons were prepared. At the end of the project students were asked to write a written report. The sample comprised 40 students. Respondents $(n=40)$ were asked to rate the extent that they agreed $(-2=$ strongly disagree; $-1=$ disagree; $0=$ neutral; $1=$ agree; and $2=$ strongly agree. attitudes toward the laboratories and $90 \%$ of students had a positive attitude about the hands on practice attending laboratories. This increased their confidence and motivation. Also students' grades were compared to other allied subjects; there was a positive correlation between osteology and other systems and between anatomy and histology, embryology physiology and biochemistry. Furthermore the project motivated student and were able to upgrade from superficial to deep learning strategies. It also encouraged collaboration among students and they were able to form spontaneously a study group which functioned as a unit of team base learning.
\end{abstract}

Keywords: Skeleton, anatomical museum, learning styles, cognitive learning, educational motivation

\section{Introduction}

Veterinary anatomy is one of the most important subjects in the veterinary curriculum and it is the main foundation of veterinary medicine. Veterinary anatomy is one of the oldest basic medical sciences. Hippocrates (460 - 377 BC), is considered the father of medicine and founder of the science of anatomy, Claudius Galen (130-210 AD) learned anatomy at Alexandria Medical School and wrote a book on medical anatomy on the basis of the structures of animals 
such as sheep, dog, bear, pig and ox. Though his main purpose was to study human anatomy yet his investigations became landmarks in Veterinary Anatomy (Tan, 2002). But while the subject matter may not have changed all that much, the ways of teaching anatomy have undergone dramatic changes over the past few decades (Ling, 2007; Norman, 2010). In the conventional curriculum, veterinary anatomy is taught methodically, where various systems of the body are taught first. And the related histology, embryology physiology and biochemistry are taught together. The systemic approach gives a holistic view with a good understanding of the body systems and the mutual relationship of the organs. Most first year student regarded anatomy as a difficult subject due to the burden of nomenclature, descriptive nature of the subject matter, little interactive activity and the view that anatomy is dogmatic subject (Sissons, et al., 1975; Notebaert, 2009). In essence, cognitive load theory proposes that since working memory is limited, learners may be bombarded by information and, if the complexity of their instructional materials is not properly managed, this will result in a cognitive overload. This cognitive overload impairs schema acquisition, later resulting in a lower performance (Paas et al., 2004). Moreover, the teaching of anatomy has been administered in the same way since the times of its initiation (Aversi-Ferreira, 2009), Anatomy is not growing and many people are reluctant to teach (McCuskey et al., 2005; Purkayastha, and Paraskevas 2007). Motivation refers to "a student's willingness, need, desire and compulsion to participate in, and be successful in the learning process (Yunus and Ali, 2009). Intrinsic and extrinsic motivation plays a large part in students' interest in and enjoyment of school and study. Conversely it is important for the instructor to motivate students or change their attitude to words anatomy at the outset. First impressions about a subject matter are very important this may lead to self motivation or self inhibition. We all judge many things on first impressions. De-motivated students are less likely to make effort and will follow superficial rather than deep learning strategy (Ames and Archer, 1988); such students are always worried and continuously fear exams or contemplate of poor academic performances.

The first chapter taught in many anatomy courses is osteology. Thus the skeleton becomes more important teaching aid. Hands on teaching aids are extremely valuable for all aspect of cognitive learning. Often skeleton can complement teaching methods allowing visualization and actual structures of the animal body. Young people can learn most readily about things that are tangible and directly accessible to their senses visual, auditory, tactile, and kinesthetic (Paas et al. 2004). With experience, they grow in their ability 
to understand abstract concepts, manipulate symbols, reason logically, and generalize. These skills develop slowly; however, the dependence of most people on concrete examples of new ideas persists throughout life (Paas, 2003). Thus the objective of this study was to assess the impact of teaching anatomy with the help of student hands on projects to evaluate the student motivation, attitude and cognition behavior in learning veterinary anatomy.

\section{Materials and Methods}

\section{Skeleton preparation:}

The skeleton preparations were undertaken in Mekelle, Wollo and Jijiga universities. The following animal species were used: three oxen, two camels, one horse, two sheep, two goats, one dog, and five poultry were purchased. Additional limb bones and cranium were purchased from butchers shop. About 4-10 students formed a group then assigned to process the skeletons.

Deboning: The animals were slaughtered and skinned. And deboned on the same day, all meat was removed by knife. Holes were drilled in the ends of bone of the wet skeleton proximal and distal parts of a joint by means of a hand tool power driller using $1-3 \mathrm{~mm}$ drill bite gauges. Then the bones of the fore and hind limbs were jointed using craft wire 1.5- 4 gauges. The neck was disarticulated from the cranium and thorax. Then 20-30 $\mathrm{mm}$ gauge wire was passed through the intervertebral canal. The heads of the ribs were drilled and attached to their respective thoracic vertebra. The sterna ribs were also fixed to the sternum. The asternal ribs were attached by twisting a wire against each other. This procedure reduced the time to assemble the skeleton and facilitate the removal of marrow from bones during boiling. The size and length of the wire depended on the size of the bone.

Degreasing and Cleaning: The partially articulated skeleton, fore and hind limbs, lumbar and sacral vertebra, the thorax, the cervical vertebra and the head were boiled fully covered in water in a metal container $(1.5 \mathrm{~m} \times 1 \mathrm{~m} \mathrm{x}$ $1.25 \mathrm{~m}$ ) for large animals while for small animals we used small cooking pot. The boiling facilitated the remaining tissue to become loose and the removal of fat was speeded up by simmering up to 3 times removed grease. The time required for boiling depended on the condition of the carcass at the start and the size .The boiling time and procedure is shown on Table 1. Because over boiling discolors and damages the skeleton. Scapular cartilage were not boiled but were subjected to all other processing procedures. Also fragile and small bones were boiled separately in small container to keep them from disappearing 
during the simmering process. Once the soft tissues were scraped off, the bones were soaked in water with detergent $\mathrm{OMO}^{\circledR}$ and bleach for a day .Next; the bones were dried in the sun for two days and were immersed in sealed container filled with gasoil sufficient enough to accommodate the bones. The bones were left for a week. And then removed and dried for two days. The bones were again soaked in thinning lacquer containing acetone for a week. The bones are then dried.

Table 1. Recommended processing time (in days) and procedures for preparation of dry-skeleton

\begin{tabular}{llccc}
\hline Steps & Processes & Ovine and Canine & Bovine and equine & Camel \\
\hline 1 & Slaughtering and deboning & 1 & 1 & 1 \\
2 & Stitching with wire & 1 & 1 & 1 \\
3 & Boiling & 0.25 & 0.8 & 1 \\
4 & Scraping remains & 1 & 2 & 3 \\
5 & Soaking in Soap and bleach & 3 & 7 & 10 \\
6 & Soaking in gasoline & 7 & 7 & 10 \\
7 & Soaking in 5\% formalin & 7 & 7 & 10 \\
8 & Air Drying & 7 & 7 & 10 \\
9 & Mounting & 1 & 1 & 1 \\
\end{tabular}

Bone assembly and mounting :Finally the bones were painted with $30 \%$ hydrogen peroxide and were immediately dried in the sun. Then the wires which were used for reattaching bones were replaced with a new galvanized wire and the skeleton is mounted on a platform as shown on Figure 1. The names of the parts of the armature and their dimensions are depicted in Table 2 . In addition to full skeleton mounts artistic gluing of poultry skeleton, bovine lower limb and an anatomical display cabinet were set for individual bones and collection of skull from different species. And an exhibition titled "Body and Mind" man plowing with a pair of oxen was also displayed as part of the project. 


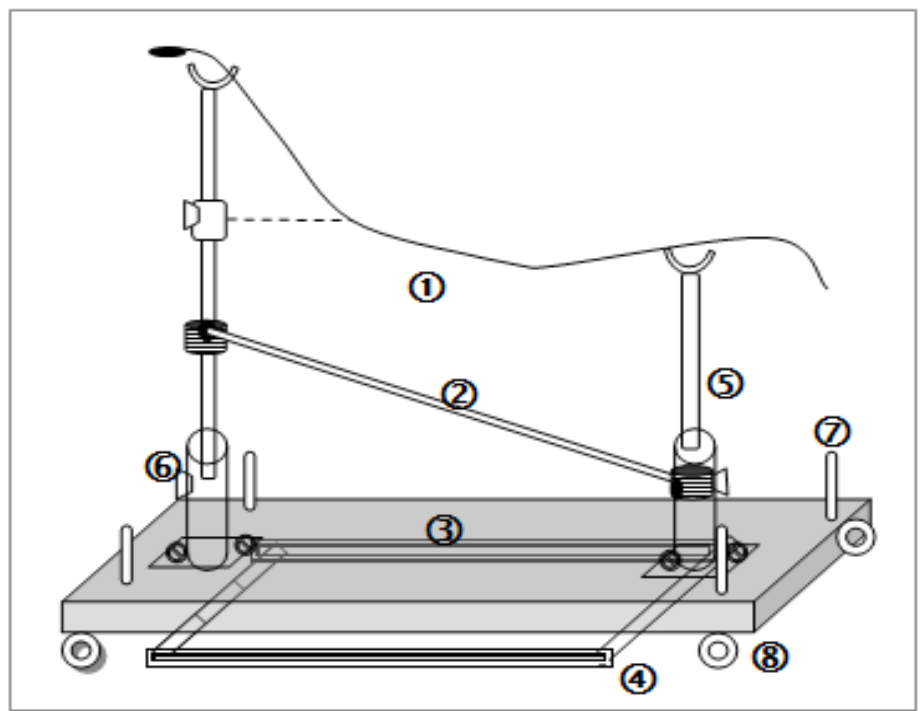

Figure 1. Diagram of skeletal armature

Table 2. Skeleton aperture parts and dimensions (in $\mathrm{cm}$ )

\begin{tabular}{llccc}
\hline $\begin{array}{l}\text { Part } \\
\text { No. }\end{array}$ & Part name & $\begin{array}{c}\text { Ovine and } \\
\text { Canine }\end{array}$ & $\begin{array}{c}\text { Bovine and } \\
\text { equine }\end{array}$ & Camel \\
\hline 1 & Axial support & 75 & 190 & 210 \\
2 & Horizontal cross bar & non & 150 & 170 \\
3 & Wooden platform & $2.5 \times 50 \times 100$ & $2.5 \times 60 \times 200$ & $2.5 \times 60 \times 210$ \\
4 & Bottom metal frame & $40 \times 190$ & $50 \times 180$ & $50 \times 200$ \\
5 & Top sliding bar forked & 70 & 100 & 120 \\
6 & Bottom tube for sliding bar & 60 & 100 & 100 \\
7 & support & & & 40 \\
8 & Appendage support & 15 & 50 & 5 \\
\hline
\end{tabular}

\section{Multimedia preparation:}

Once the skeletal specimens were prepared photographs were taken individual structures and partially and whole articulated skeleton. Using Canon digital camera IXUS 750 and a video film was produced using Sonny handcam HDRCX7 6.1 MEGA pixel. Or students have drawn structures manually. The photographs were labeled and edited in Photo editor (Photos cape ver. 3.5). A sound system was added to the video track so that students can listen and 
memorize the vocabulary with correct pronunciation. Students were asked 10 minute seminar presentation mainly on the osteological structure from the multimedia.

\section{Impact assessment:}

A debriefing questionnaire was administered at the end of the course .Impact was assessed using measuring instruments student cognitive performance by applying exam in osteology and final exams in all systems. Correlation of anatomy grades to Physiology, histology, biochemistry and embryology grades was also done. Exams to assess deep knowledge that is understanding concepts and superficial knowledge which is memorization questions were administered to discriminate between learning styles and strategies, the results obtained were reported as deep exam grade and grade superficial exam grade. Impact of on student motivation was assessed using class attendance and a five scale measure questionnaire $(-2=$ strongly disagree; $-1=$ disagree; $0=$ neutral; $1=$ agree; and $2=$ strongly agree) as measure, student attitude and team based learning.

\section{Statistical analysis:}

Descriptive statistics was made using Microsoft EXCEL software.

\section{Results}

Using this simplified method of skeleton preparation; students were able to produce 10 skeletal models as shown on plate 1 , plate 2 and palate 3 . The photos in plate 3 show that a lateral, frontal and caudal view of a man plowing with a pair of oxen. The human skeleton was a plastic model. The students have given it a title "Body and mind" showing the relationship between man animals and the environment. This exhibition has attracted many visitors including a university President. 

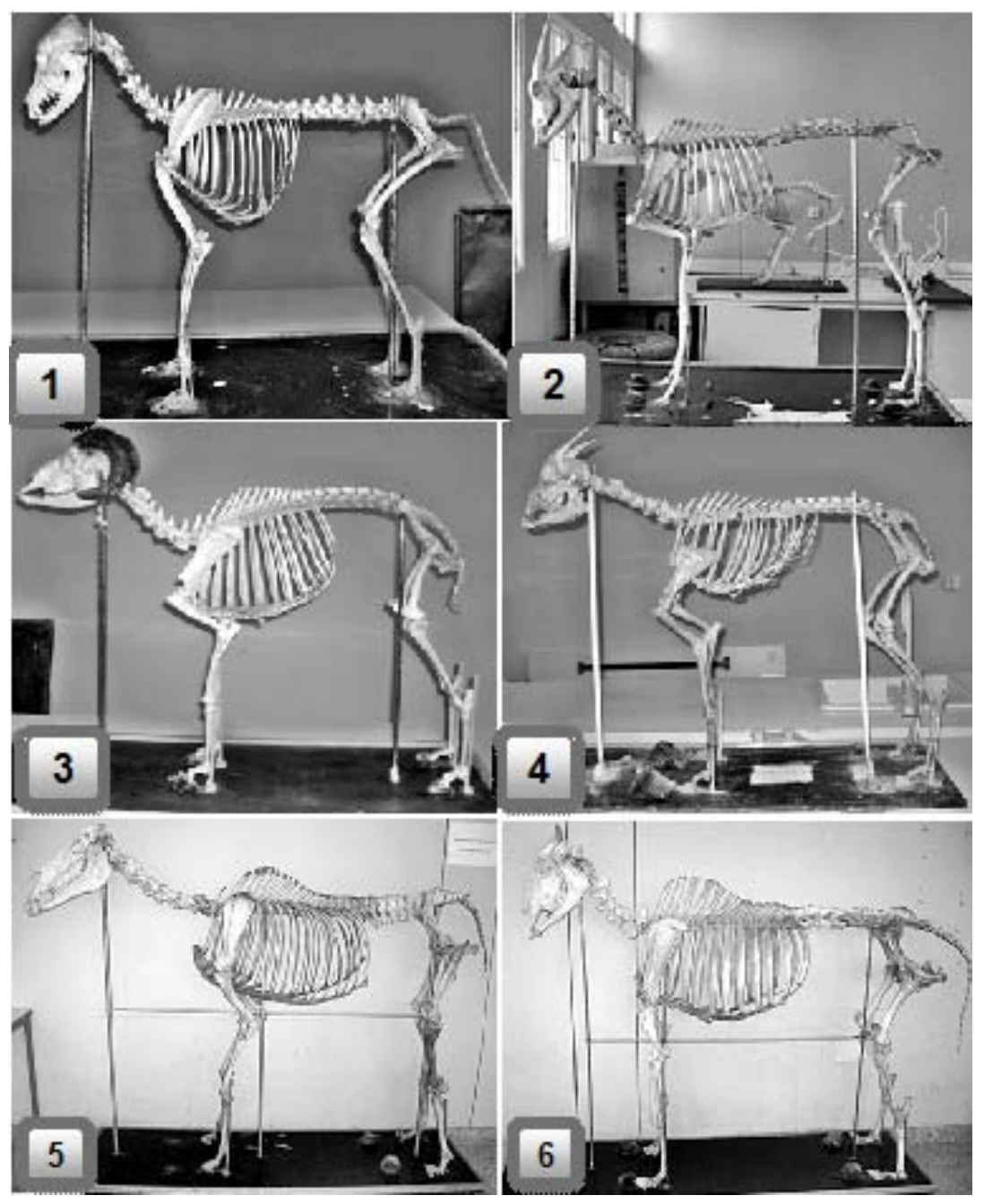

Plate 1. (1) Canis familaris, male, Basenji; (2) Capra aegagrus hircus; (3) Ovis aries,;( 4) caprine spp; (5) Equus cabalaus Abyssinian pony and (6) Bos indicus , zebu cow 

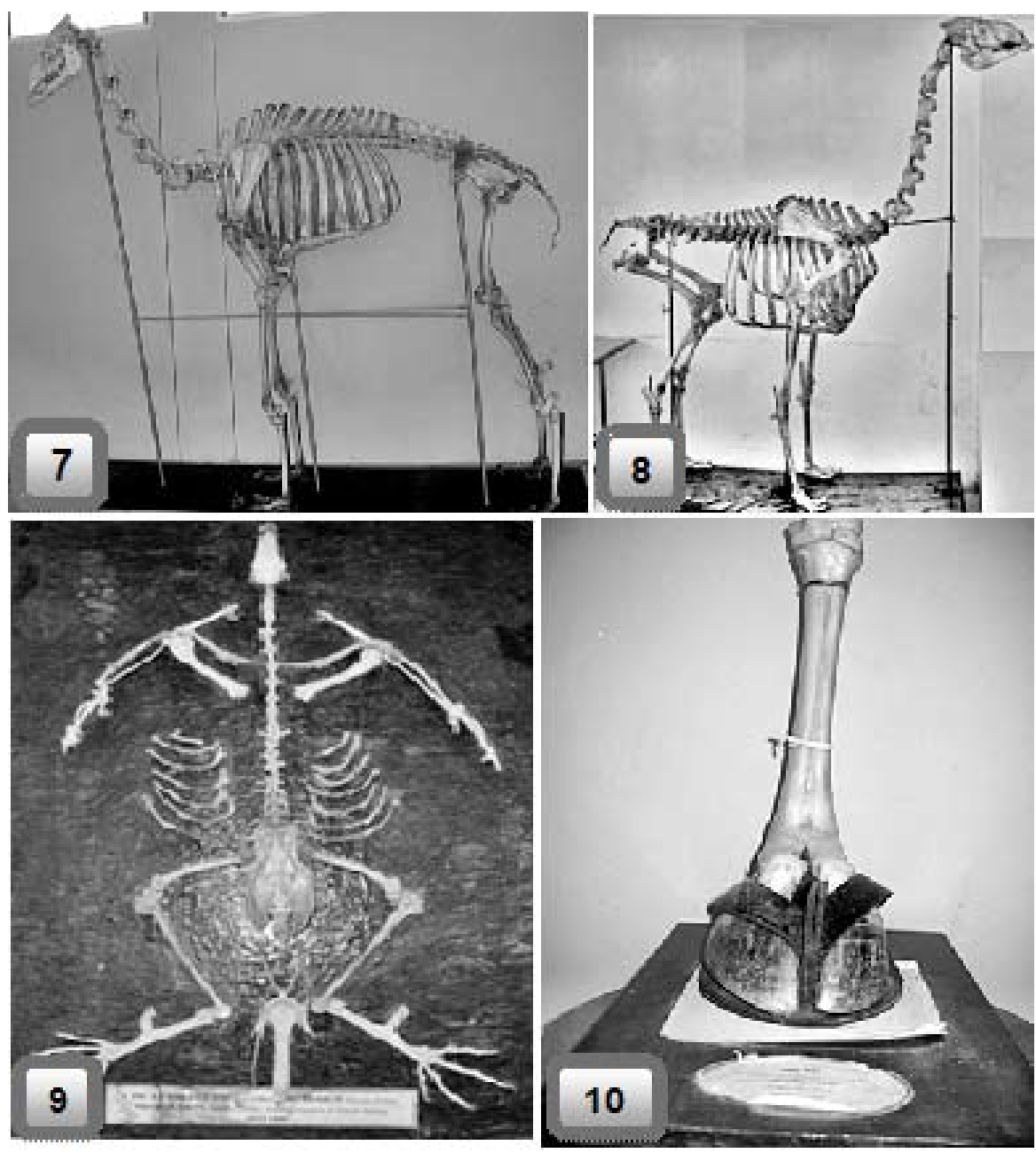

Plate 2. (7) and (8) Camelus dromedarius, Galus galus domesticus and lower foreleg bone bovine and a shoe 


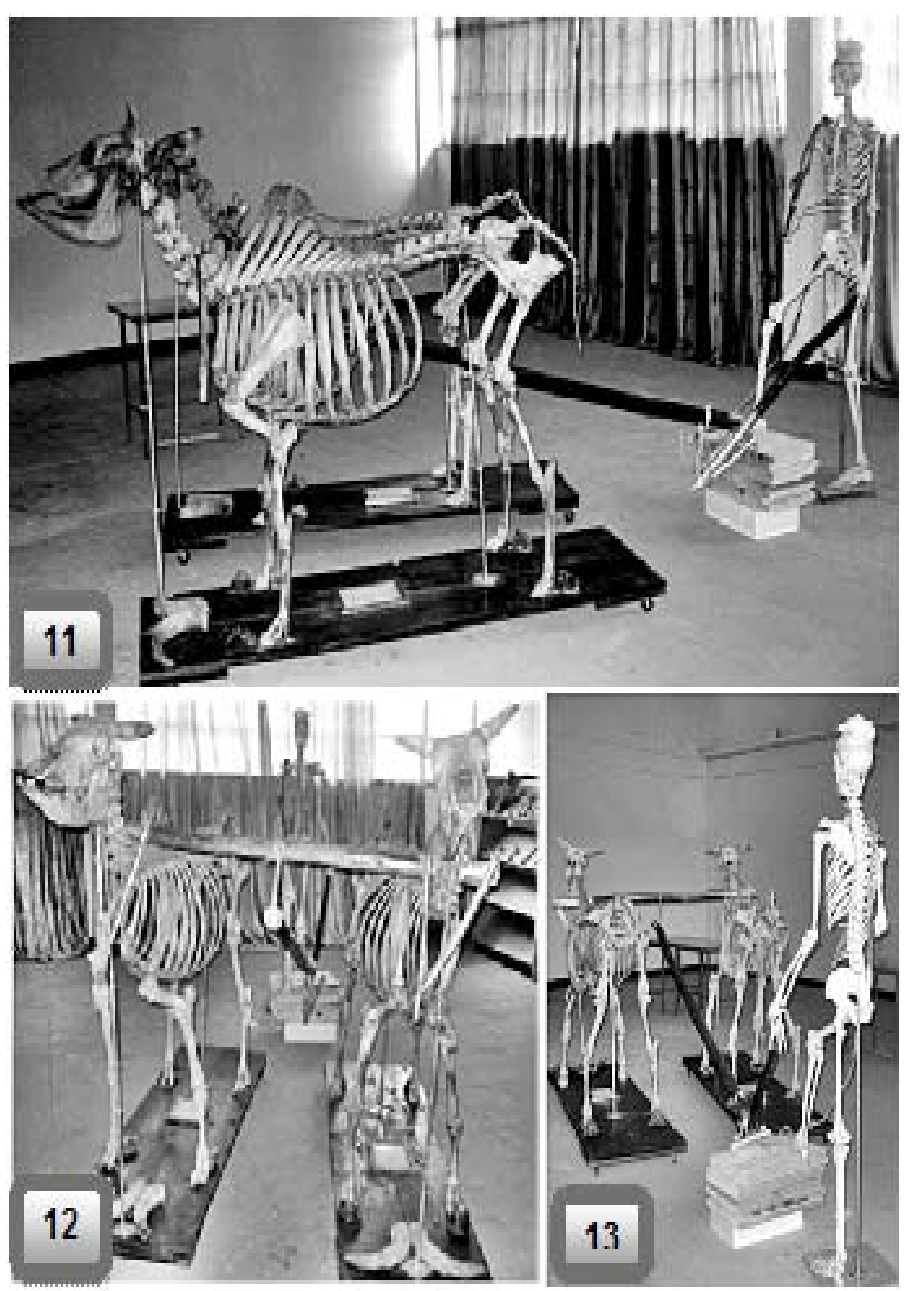

Plate 3. A plowman and a pair of plow oxen

The student responded such teaching method was useful to them as shown on Figure 2. None of the students had a negative response about the teaching activity. The students have also responded positively that they were motivated by the project their learning style has shifted from superficial memory versus understanding concepts deep style. The hands on activity also motivated students as measured from class attendance which was $95 \%$, relatively many students missed the first day class $20 \%$ as shown in Figure 3. Additional data 
on student motivation is shown in Table 3 most of the students agreed that they were stimulated by the hands on project and non has disagreed.

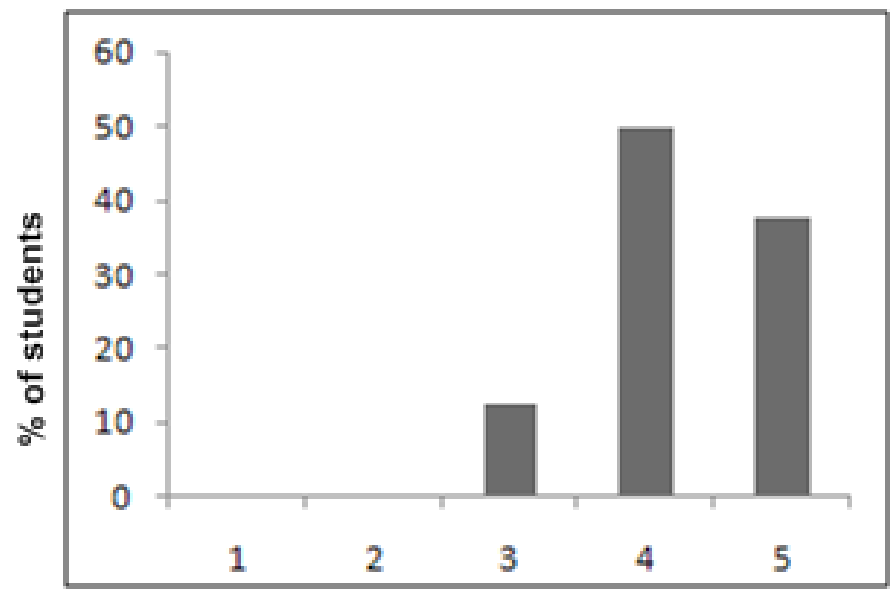

Type of response

Figure 2. Students response on the importance of the project to learning (1=strongly disagree;2= disagree; $3=$ neutral; $4=$ agree; and $5=$ strongly agree.

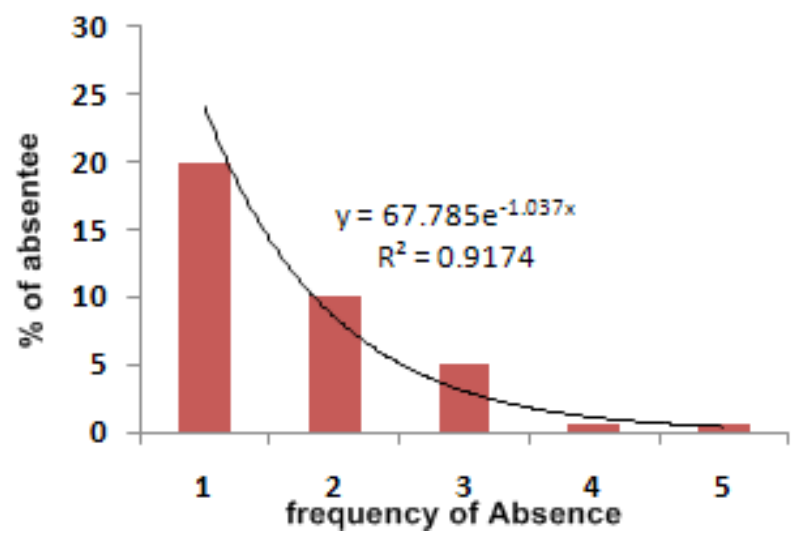

Figure 3. Students class attendance 
Table 3. Student total scores on motivation*

\begin{tabular}{llllll}
\hline Motivation & $\begin{array}{l}\text { Strongly } \\
\text { Disagree }\end{array}$ & Disagree & Neutral & Agree & $\begin{array}{l}\text { Strongly } \\
\text { Agree }\end{array}$ \\
\hline Study time increased & 0 & 0 & 2 & 18 & 60 \\
Effort to get reference & 0 & 0 & 0 & 8 & 72 \\
Work hard & 0 & & 6 & 20 & 54 \\
Like the lab & 0 & 0 & 0 & 2 & 78 \\
Dislike the lab & 76 & 2 & 0 & 0 & 0 \\
Confidence & 4 & 8 & 18 & 16 & 34 \\
Skill & 0 & 14 & 12 & 14 & 40 \\
Reduced worrienes & 6 & 16 & 20 & 20 & 1 \\
New Knowledge & 0 & 0 & 6 & 24 & 50 \\
\hline Team learning & 0 & 0 & 0 & 4 & 76 \\
\hline
\end{tabular}

*(n=40)

Cognitive learning was assessed using student grade in anatomy, the result is shown on Table 4. Anatomy grade A was positively correlated with basic science grades namely physiology, biochemistry histology and embryology. Further more students who scored good grades in osteology that are, 32 out of 40 have scored A in anatomy final exam. The examination for deep questions mid exam was 12 out of 20 while in the final was 26 out of 30 a slight improvement in overall performance.

Table 4. Comparison of Anatomy grade to an A grade in other subjects

\begin{tabular}{lcccc}
\hline A grade & Physiology & Biochemistry & Histology & Embryology \\
\hline $\begin{array}{l}\text { Anatomy Grade } \\
\text { A or B }\end{array}$ & 36 & 31 & 38 & 27 \\
$\begin{array}{l}\text { Anatomy Grade } \\
\text { C or D }\end{array}$ & 6 & 0 & 0 & 0 \\
\hline
\end{tabular}

\section{Discussion}

Our results confirm that student performance can be enhanced through hands on practice. Some authors have introduced alternative methodologies such as digital images which are well accepted by students and thus, learning became more effective (Shaffer, 2004; Ling, 2007. However, digital images did not produce the desired attitude change towards dissection and anatomy lab (Winkelmann, 2007; Aversi-Ferreira, 2010). Thus the use of a combination of methods is recommended as it increases learning channels. The hands on pedagogy facilitated learning according to responses in this study, because it allowed a more active and participatory learning and each student was able 
to learn on his own way and time using the prepared multimedia. Cognitive learning, is a dynamic process, leading to the construction of knowledge, it requires the acquisition of knowledge and the ability to process it and store it in memory (Novac, 1990). This requires more active methods.Only in this way, learning can be effective. Therefore cognitive learning is different from the simple acquisition of information afforded by the traditional paradigm. Thus, learning occurs more effectively when the student experiences the content or objects of knowledge (Whittaker and Fyef, 1998), using various channels of reception and processing of information such as auditory, visual, tactile, kinesthetic, and others (Reid, 1987). The use of active methodologies by the teacher facilitates the construction of knowledge by the student, making students not mere receivers of information. According to Novoa, (2002) cited by (Mota et al., 2010), the success of the teacher depends on the active cooperation from the student.

Veterinary gross anatomy is a foundational course for many allied health programs. Because it is a heavily weighted course, usually carrying 5 or more semester credits, a high grade is important to help insure good academic standing. Thus give students opportunities to succeed at the beginning of the semester. Once students feel they can succeed, you can gradually increase the difficulty level. If assignments and exams include easier and harder questions, every student will have a chance to experience success as well as challenge (Gross, 1999).

The students agreed they have increased effort to study as measured attempt to access a material, increased study time and taking notes thus a shift from on a surface approach to learning (relying on rote memorization and knowing factual information) to deep approach to learning (understanding concepts and deeper meaning students). Students who practiced the hands on exercise demonstrated greater confidence and proficiency in later assignments that required anatomical and taxonomic identification of isolated bones (Pandey and Zimitat 2007).

There is growing evidence that team-based learning (TBL) is an effective way of incorporating interactive small group peer teaching and enthusiasm for learning. Increasingly, courses are being taught using TBL in both undergraduate and graduate 1 education recent reports include the use of TBL in anatomy teaching students formed study groups (Vasan, 2009). In this study students were asked to work in groups and all students had a positive attitude. 
In order for teachers and students to be protagonist of the teaching-learning process, there should be motivation to learn (Zhou, 2010), it is up to the teacher the selection of the teaching procedures most suitable for the construction of knowledge by students (Ganguly, 2010). Unfortunately, there is no single magical formula for motivating students. Many factors affect a given student's motivation to work and to learn (Martin, 2003): interest in the subject matter, perception of its usefulness, general desire to achieve, self-confidence and selfesteem, as well as patience and persistence. And, of course, not all students are motivated by the same values, needs, desires, or wants. Some students will be motivated by the approval of others, some by overcoming challenges. (Azman, 2005) described three educational attitude, students with the academically apathetic attitude those who do not recognize the importance of an education or a degree, students with the occupation-driven attitude who recognize the importance of a degree but not necessarily an education, they see a baccalaureate degree as the best way to get a job and lastly, the students with the scholar attitude enjoy learning. They are mastery oriented.

Researchers have begun to identify those aspects of the teaching situation that enhance students' self-motivation (Ames and Archer, 1988 ; Zhou, 2010)To encourage students to become self-motivated independent learners, instructors can do the following: Some students seem naturally enthusiastic about learning, but many need-or expect-their instructors to inspire, challenge, and stimulate them: "Effective learning in the classroom depends on the teacher's ability to maintain the interest that brought students to the course (Gross, 1999 ). Thus innovative approach in teaching learning of veterinary gross anatomy is a key factor to motivate students and teachers.

Besides the enhancement of cognitive learning by the hands on practice, the skeletal preparations became properties of the anatomical museums. And these is known to be useful and motivates further (Basmajian, 1961; Harrison et al. 2001; Deratzian, and Alison, 2010) . Thus active participation of students in hands on anatomical practice has a many fold advantages in teaching learning by creating an attractive teaching environment, increasing learning chanales and motivating students. 


\section{Reference}

Ames, C. and Archer J., 1988. Achievement Goals in the Classroom: Students' Learning Strategies and Motivation Processes. J. Educ Psychol80: (3) 260-267

Aversi-Ferreira, T. A., Nascimento, G., Vera I. and. Lucchese, R., 2010. The practice of dissection as teaching methodology in anatomy applied to medical education. Int. J. Morphol. 28:(1)265-272

Aversi-Ferreira, T.A., Lope, D.B., Reis, S.M., Abreu, T., Aversi-Ferreira, R, Vera, I. and Lucchese, R., 2009. Practice of dissection as teaching methodology anatomy for nursing education. Braz. J. Morphol. Sci. 26: (3-4)151-157

Azman, R., 2005. The development of the scale of educational attitudes. Journal of College Teaching \& Learning. 2: (4) 51-64

Deratzian, T. and Alison, R., 2010. The museum gallery as anatomy classroom: teaching geology students comparative osteology without inciting mass panic. 2010 GSA Denver Annual Meeting. http:/gsa.confex.com/gsa/2010AM/finalprogram/ abstract_179988.htm

Ganguly, P.K., 2010. Teaching and learning of anatomy in the 21st century: Direction and the strategies. The Open Medical Education Journal. 3: 5-10

Harrison, J., Nichols, S. and Whitmer A., 2001. Evaluating the impact of physical renovation, computerization, and use of an inquiry approach in an undergraduate, allied health human anatomy and physiology lab .Adv. Physiol. Educ. 25:202-210

Basmajian, J.V.,1961. The modern anatomy museum as a teaching aid. The Anatomical Record 139: (3) 363-368. DOI: 10.1002/ar.1091390304 Copyright (C) 1961 WileyLiss, Inc.

Ling, B., 2007. Teaching of Anatomy in the new millennium. Singapore Med J. 48: (3) 182-183.

Martin, A.J., 2003. The Student Motivation Scale: further testing of an instrument that measures school students' motivation. Australian Journal of Education. 47: 88-106.

McCuskey, R., Carmichael, S. and Kirch, D., 2005. The Importance of anatomy in health professions education and the shortage of qualified educators. Academic Medicine. 80: ( 4 ) 349-351 
Mota, M. F., Mata, F. R. and Aversi-Ferreira, T. A.,2010. Constructivist pedagogic method used in the teaching of human anatomy. Int. J. Morphology. 28: (2)369374

Norman, G., 2010. Anatomical mysteries. Adv. in Health Sci. Educ. 15:149-151. DOI 10.1007/s10459-010-9227-6

Notebaert, A., 2009 . Student perceptions about learning anatomy. PhD diss., University of Iowa, 2009. http://ir.uiowa.edu/etd/312.

Novac, J.D., 1990. Concept maps and Vee diagrams: two metacognitive tools to facilitate meaningful learning. Instructional Science Volume 19, Number 1, 29-52, DOI: 10.1007/BF00377984

Paas, F.., Renkl, W. C. and Sweller, J., 2004. Cognitive load theory: instructional implications of the interaction between information structures and cognitive architecture. Instructional Science. 32: 1-8.

Paas, F., Tuovinen, J. E., Tabbers H. K. and Van Gerven P., 2003. Cognitive load measurement as a means to advance cognitive load theory. Educ. Psychol., 38 (1), $63-71$.

Pandey, P. and Zimitat, C., 2007. Medical students' learning of anatomy: memorization, understanding and visualization. Medical Education. 41 :(1)7-14.DOI: 10.1111/ j.1365-2929.2006.02643.x

Purkayastha, S. and Paraskevas P., 2007. Anatomy crisis: Make surgeons more active in teaching anatomy at all levels. BMJ . 334:110 doi:10.1136/bmj.39094.394606.1F

Shaffer , K.,2004. Teaching anatomy in the digital world. N. Engl. J. Med. 351:12791281

Sissons, S., Grossman J. and Getty R., 1975. The anatomy of domestic animals. 5th eds. Sounders Company USA.

Tan, S.Y., 2002. Medicine in Stamps Galen (130-201 A.D.): History's most enduring medic. Singapore Med. J. 43: (3)116-117. http://www.sma.org.sg/smj/4303/4303ms1. pdf. Accessed 3 March 2011

Vasan, N.S., DeFouw D.O, and Compton S., 2009. A survey of student perceptions of team-based learning in anatomy curriculum: favorable views unrelated to grades. Anat Sci Educ. 2:(4)150-155 
Whittaker, G. and Fyfe. G., 1998. Student participation in plastination as a learning exercise in a science degree embryology unit. J. Int. Soc. Plastination 13 (1) 2629

Winkelmann, A., 2007. Anatomical dissection as a teaching method in medical school: a review of the evidence. Med Educ. 41:(1):15-22

Yunus, A. and Ali, W., 2009. Motivation in the learning of mathematics. European Journal of Social Sciences. 7: ( 4 ) 93-101

Zhou, G., 2010. Conceptual change in science: a process of argumentation. Eurasia Journal of Mathematics, Science \& Technology Education. 6:(2), 101-110 